The research program of the Center for Economic Studies (CES) produces a wide range of theoretical and empirical economic analyses that serve to improve the statistical programs of the U.S. Bureau of the Census. Many of these analyses take the form of CES research papers. The papers are intended to make the results of CES research available to economists and other interested parties in order to encourage discussion and obtain suggestions for revision before publication. The papers are unofficial and have not undergone the review accorded official census Bureau publications. The opinions and conclusions expressed in the papers are those of the authors and do not necessarily represent those of the U.S. Bureau of the Census. Republication in whole or part must be cleared with the authors.

PRICES, SPATIAL COMPETITION, AND HETEROGENEOUS PROCEDURES: AN EMPIRICAL TEST

by

\author{
Chad Syverson* \\ University of Chicago
}

CES 04-16 August, 2004

All papers are screened to ensure that they do not disclose confidential information. Persons who wish to obtain a copy of the paper, submit comments about the paper, or obtain general information about the series should contact Sang $V$. Nguyen, Editor, Discussion Papers, Center for Economic Studies, Washington Plaza II, Room 206, Bureau of the Census, Washington, DC 20233-6300, (301-763-1882) or INTERNET address snguyen@ces.census.gov. 


\title{
Prices, Spatial Competition, and Heterogeneous Producers: An Empirical Test ${ }^{*}$
}

\author{
Chad Syverson \\ University of Chicago \\ syverson@uchicago.edu
}

August 2004

\footnotetext{
* An earlier version of this paper was titled, "Price Dispersion: The Role of Product Substitutability and Productivity." I thank John Haltiwanger, Saul Lach, Aviv Nevo, Ken Troske, and participants at various seminars for helpful comments. Mark Roberts and Lucia Foster offered generous help in identifying imputed quantity data in the Census of Manufactures. The research in this paper was conducted while the author was a research associate at the Center for Economic Studies, U.S. Bureau of the Census. Research results and conclusions expressed are those of the author and do not necessarily indicate concurrence by the Bureau of the Census or the Center for Economic Studies. This paper has been screened to ensure that no confidential information is released. Correspondence can be addressed to the author at the Department of Economics, University of Chicago, 1126 E. $59^{\text {th }}$ Street, Chicago, IL 60637.
} 


\begin{abstract}
In markets where spatial competition is important, many models predict that average prices are lower in denser markets (i.e., those with more producers per unit area). Homogeneous-producer models attribute this effect solely to lower optimal markups. However, when producers instead differ in their production costs, a second mechanism also acts to lower equilibrium prices: competition-driven selection on costs. Consumers' greater substitution possibilities in denser markets make it more difficult for high-cost firms to profitably operate, truncating the equilibrium cost (and price) distributions from above. This selection process can be empirically distinguished from the homogenous-producer case because it implies that not only do average prices fall as density rises, but that upper-bound prices and price dispersion should also decline as well. I find empirical support for this process using a rich set of price data from U.S. readymixed concrete plants. Features of the industry offer an arguably exogenous source of producer density variation with which to identify these effects. I also show that the findings do not simply result from lower factor prices in dense markets, but rather because dense-market producers are low-cost because they are more efficient.
\end{abstract}




\section{Introduction}

When spatial product differentiation is important, theory typically associates higher producer densities - the number of producers per unit area — with more intense competition and lower prices in a market. Closer producer spacing raises substitution possibilities for consumers, raising the cross-price elasticities of producers' residual demand curves and lowering optimal markups and prices. ${ }^{1}$ This effect is manifested in, for example, Salop's (1979) spatial competition model. Exogenous increases in consumer density (the number of purchasers dispersed around the unit-circumference circular market) yield equilibria with more and closerspaced producers and a lower equilibrium price. A similar mechanism is also appealed to (though the spatial element is implicit) in Bresnahan and Reiss (1991), which infers differences in the intensity of competition from the response of the number of producers to market size differences.

A typical assumption in such models is that producers have homogeneous production costs. Thus they only describe the response of the average (unique) price in a market to shifts in the intensity of competition. In the more realistic case where producers have different costs, there are richer predictions regarding spatial competition's effect on prices. Indeed, heterogeneous-producer frameworks imply a new, selection-based channel through which competition influences equilibrium prices (though the above effect on markups can remain as well). This paper describes this new mechanism, tests for it in an industry where spatial competition is significant, and finds support for its implications.

The basic intuition of the mechanism can be put rather simply. Increases in the toughness of competition strengthen the selection process that eliminates relatively inefficient (high-cost) producers from the market. This truncates the equilibrium production-cost distribution from above, and this is in turn reflected in a truncated equilibrium price distribution. Therefore with heterogeneity, more competitive markets exhibit not only lower average prices, as the homogeneous-producer frameworks imply, but also lower upper-bound prices and (given some additional regularity assumptions on the underlying cost distribution) less price dispersion. ${ }^{2}$ In

\footnotetext{
${ }^{1}$ However, Ohta (1981) discusses a few exceptions to the conventional wisdom.

${ }^{2}$ Given the spatial nature of the market, one could of course observe dispersion in delivered prices in the homogeneous-producers case because of differing transport costs across consumers. However, factory-door/free-onboard prices - those for which I have data in this study-would be equal. In the heterogeneous-producers case, however, free-on-board prices exhibit dispersion. Note also that a simple generalization of the homogenousproducers model to allow for noisy prices (say from mismeasurement) would not fit the implications of the
} 
other words, competition among heterogeneous producers shapes the equilibrium price distribution through its impact on the equilibrium cost distribution.

I present below empirical evidence regarding the interaction between spatial competition and equilibrium prices. In a case study of the ready-mixed concrete industry (SIC 3273), I find strong support for the conventional wisdom that average prices tend to be lower in markets where spatial competition is expectedly more intense. (I describe the measurement of competition intensity and argue its exogeneity below.) However, I also document nontrivial within-market price dispersion, and find that this dispersion as well as the upper-bound market price both fall with increases in competition. These results suggest that competition-driven selection among heterogeneous-producers is important to understanding prices in industries where transport costs are nontrivial.

I go on to show that these price patterns do not seem to result from systematic differences in input costs across markets, further suggesting that the selection mechanism is acting along the efficiency margin, weeding out the less efficient in more competitive markets. This is consistent with evidence I have found in previous work (Syverson 2004a, 2004b) that product substitutability, spatial or otherwise, shapes equilibrium productivity distributions.

The paper intermeshes conceptually with the previous empirical literature along two primary dimensions. Recent research such as Sorensen (2000), Goolsbee and Brown (2002), and Chevalier and Goolsbee (2003), has inferred consumers' substitution possibilities from observed price dispersion. These papers rely on differences in search incentives or technology (e.g., repeat purchases or access to the internet) to identify substitutability changes driven by increases in search intensity. In this paper, the analysis explicitly spatial since transport costs are the source of consumers' limited substitution opportunities. The focus on the transport-cost-intensive ready-mixed concrete industry also offers, as I will explain below, exogenous variation in competitiveness across a large number of geographically independent markets, allowing considerable empirical leverage in observing equilibrium price effects.

The paper's second point of contact with the literature is the research on selection mechanisms in heterogeneous-producer industries. Empirical work in this area, such as Baily, Hulten, and Campbell (1992); Olley and Pakes (1996); Foster, Haltiwanger, and Krizan (2002)

selection-driven mechanism. Selection acts asymmetrically on the cost and price distributions, implying changes in the upper-bound and dispersion of the distributions that noise alone would not create. 
has shown that competitive forces tend to drive out less efficient producers in industry equilibrium. I show evidence here that these mechanisms also seem to be important in creating and shaping equilibrium price distributions across markets. While the results are obtained for a particular industry, given the empirical ubiquity of price dispersion for what may at first glance be homogeneous goods, it is likely that the mechanisms extend their reach beyond the readymixed concrete industry alone.

\section{Conceptual Framework}

\section{A. Competition-Driven Selection}

Because of space considerations, I present here an intuitive discussion of the theoretical framework for selection-driven price distribution effects in lieu of presenting a formal model. However, models yielding such results can be found in Syverson (2004a and 2004b). ${ }^{3}$ (The latter is explicitly spatial and is most directly applicable to the ready-mixed concrete industry, though both yield the same implications with regard to the shape of the equilibrium price distribution.)

Consider entry into a market as a two-stage, simultaneous move game. In the first stage, ex-ante identical producers decide, upon observing the level of demand, whether to take an initial entry step into the market. If they choose to do so, they incur a sunk cost and then learn their own (constant) marginal cost of production. This marginal cost is drawn from a distribution common to all entrants. Upon learning its cost level, the firm then decides whether or not to commence production, which entails another fixed cost. ${ }^{4}$

Two conditions are imposed on the equilibrium: no producer operates at a loss (they can always forgo production and earn nothing, though they must forfeit any sunk costs if so), and entry occurs until ex-ante expected profits (i.e., before sunk entry costs are paid and cost draws are learned) are zero. Because a producer's operating profits decrease in its marginal cost, the former condition implies there must be a critical marginal cost draw such that a producer with

\footnotetext{
${ }^{3}$ Some additional models of selection among heterogeneous producers in an industry equilibrium (though not all are concerned with price effects) include Hopenhayn (1992), Asplund and Nocke (2003), and Melitz (2003).

${ }^{4}$ Empirical evidence suggests that producers do sink resources into entry before learning their costs. Several papers, such as Dunne, Roberts, and Samuelson (1989); Baily, Hulten, and Campbell (1992); and Foster, Haltiwanger, and Krizan (2002) have found that young plants have higher failure (exit) rates than incumbents. Thus it seems entering producers do not typically know very well their own position relative to their competition when it comes to profitability components like production costs.
} 
this cost level earns zero operating profits. ${ }^{5}$ Those drawing costs higher than this level will choose not to produce in equilibrium.

This cutoff (zero-operating-profit) marginal cost is critical because it determines the extent of cost truncation in equilibrium. Changes in exogenous factors that shift this cutoff level to lower cost levels further truncate the distribution. Clearly, then, to understand the truncation effect of greater demand density and its concomitant increase in spatial substitutability, one needs to understand how density affects this cutoff cost level. In equilibrium, the cutoff is pinned down by the second, free-entry condition above: it is the value that sets expected profits at entry equal to zero.

To see why, consider the cutoff cost's role in the free-entry condition. The expected gross benefit of entry equals the probability of obtaining a cost draw that will yield positive operating profits multiplied by those expected operating profits. Free entry equates this value to the sunk entry cost. Clearly, a higher cutoff cost level corresponds to a higher probability of successful entry. But an increase in the cutoff level also increases the expected profits conditional on commencing production, because this lets higher-cost producers into the market, raising the average costs of any given producer's rivals. Therefore the expected value of entry increases monotonically in the cutoff cost level, implying there will be a unique equilibrium cutoff where the free entry condition holds.

Now consider the comparative static of interest: the change in the cutoff marginal cost in response to a rise in market demand (and since the market area is fixed, an increase in demand density). For simplicity, let it be simply a multiplicative increase from the previous level. In the absence of any other change in the market, this would clearly raise the expected value of entry, since each producer would sell more output at the same price. Therefore there must be a countervailing effect that lowers expected profits enough to ensure the free-entry condition holds. An increase in the number producers paying to enter the market will induce greater substitution opportunities for market consumers, lowering optimal markups and prices. If the loss in profits from lower prices is greater than the gain due to higher sales for the formerly marginal producer (and Syverson 2004a and 2004b show that this is the case), this will decrease

\footnotetext{
${ }^{5}$ We are implicitly assuming that the marginal cost distribution spans a sufficient domain so that not every draw is profitable (or unprofitable) given the size of the sunk entry and fixed production costs.
} 
the cutoff cost value. ${ }^{6}$ This in turn leads to a smaller probability of successful entry and lower expected profits from production, bringing the expected value of entry back to zero and yielding a new equilibrium with a lower cutoff cost level. There the initial increase in demand density leads to a more severe selection in the market. The upper-bound price and dispersion impacts discussed above reflect the progressive truncation of the marginal cost distribution when density rises. Furthermore, the truncation combines with lower optimal markups to result in lower average prices in denser markets.

\section{B. Ready-Mixed Concrete as a Case Study}

The U.S. ready-mixed concrete industry offers several advantages as a test case to study the equilibrium price effects of the intensity of spatial competition. I discuss these briefly here.

Ready-mixed concrete's relative homogeneity minimizes price dispersion driven by variation in vertical and/or horizontal product attributes (other than location, of course), sharpening the focus on how cost differences, rather than quality disparities, affect the price distribution. ${ }^{7}$

The industry's very high transport costs (ideal maximum delivery times are 30-45 minutes' drive from a plant) are also helpful. Besides creating the spatial nature of industry competition, they imply that the national industry is actually comprised of a number of virtually independent markets. There is considerable variation producer density and spatial substitutability across these markets. It is this disparity in producer spacing that results in differences in the toughness of competition from market to market.

\footnotetext{
${ }^{6}$ Not all producers need suffer profit decreases when substitutability rises; for instance, low-cost producers could benefit if their quantities sold become more responsive to their cost and price advantage when substitutability is higher. What is important is that the profits of relatively high-cost producers fall.

${ }^{7}$ While there are some vertical dimensions along which concrete can be differentiated (compressive strength, cure time, etc.), the impact of such differences on this study is mitigated for two reasons. First, discussions with industry managers suggest that the mix of vertical concrete types produced varies mostly within, rather than between, plants. Delivery constraints more or less require that all plants make concrete batches along the entire vertical dimension, rather than the alternative of some plants specializing in high-end product and others in low-end concrete. Thus it is likely that across-plant variation in product quality mix is small. This is also suggested by my findings below that price levels and price dispersion are smaller in dense markets. If across-plant quality variations were substantial, one might expect the opposite. Presumably the willingness to pay for quality would be higher in more urbanized areas (perhaps due to income effects), tending to raise the expected average price. Moreover, larger markets could better support producers who specialized in a particular quality, which would tend to increase observed price dispersion. These patterns are not seen in the data. Finally, to the extent that quality variation is embodied in input prices, I control for their effects in some specifications below and find that the basic results do not change.
} 
One problem with inferring the price effects of market competition by looking at markets with different producer densities is that this spacing is itself an endogenous response to the competitive environment in a market. However, the input-output patterns in the ready-mixed industry allow a way to circumvent this endogeneity. I am able to measure the density of readymixed demand using construction sector employment per square mile in the local market. This is a virtually comprehensive demand measure; the sector (SICs 15-17) buys 97.2 percent of readymixed output according to the 1987 Benchmark Input-Output Tables. Thus I observe a major determinant of producer density in local markets (the empirical correlation between demand density and producer density is roughly 0.7 ). Especially useful, though, is the fact that the demand density in a market is arguably exogenous to the nature of competition among local ready-mixed concrete plants. Because construction projects require output from a wide array of industries, the cost share of ready-mixed alone is small (only 2.0 percent of the construction sector's total costs, looking again at the 1987 Input-Output Tables). Therefore a shock to the competitiveness of the local ready-mixed industry - that would lower average concrete prices, say-is unlikely to spur a construction boom. Causation travels from construction-sector demand to concrete competitiveness, not in the reverse direction.

Focusing on the ready-mixed industry also affords the use of data from the Census of Manufactures (CM), a rich source of establishment-level production data. Unlike many economic microdata sets, the $\mathrm{CM}$ has at the detailed product level information on both establishments' revenues and physical units. This allows me to, in a given year, compute average unit prices for roughly 3100 ready-mixed plants spread across hundreds of local markets. Moreover, the CM has available information on intermediate materials input prices for a subset of these producers. This allows me to see if the key empirical findings are affected by input price differences across markets.

\section{Data}

\section{A. Output and Factor Prices}

To test the theoretical implications outlined above, I use data collected from several thousand ready-mixed concrete (SIC 3273) plants in the 1977, 1982, 1987, and 1992 Census of Manufactures (CM) Product Files. These contain plant-level data on the value of shipments by detailed (seven-digit SIC) product category. Furthermore, when feasible, annual production in 
physical units is also collected. (The unit is thousands of cubic yards for ready-mixed concrete.) This data allows unit prices to be computed at the plant level, offering an unusually rich set of producer prices from many different local markets that I exploit here. ${ }^{8}$

There are two important notes regarding these calculated unit prices. First, the value-ofshipments data is collected on a free-on-board basis, i.e., exclusive of any shipping costs. Prices should reflect not the delivered cost of the ready-mixed but rather what one could buy it for at the plant gate. This price measure better reflects the prices described in the theoretical framework and allows direct testing of the theory. The observation of lower prices in denser markets does not simply reflect shorter average shipment distances in such markets.

Second, the unit prices are annual averages, which are equivalent to a quantity-weighted average of all transaction prices charged by the plant during the year. ${ }^{9}$ Thus the prices reflect pricing decisions sustained over the course of a year, as opposed to promotional or other (uncharacteristic) temporary prices that might be captured in a single snapshot. While short-term fluctuations are interesting in their own right (and have been explored in papers such as Kashyap [1995]; Lach [2002]; and Bils, Klenow, and Kryvtsov [2003]), I am concerned here with productivity-driven price differences that are supported in long-run equilibria. Removing highfrequency price fluctuations allows clearer focus on the price dispersion source of interest.

Roughly 5200 ready-mixed plants operate in the United States. While the CM contains information on each of these, the data required to compute unit prices is not available for all plants. ${ }^{10}$ The largest excluded set, roughly one-third of plants, are Administrative Record (AR) establishments. These are very small producers (typically with less than five employees, so their

\footnotetext{
${ }^{8}$ Roberts and Supina (1996) and Beaulieu and Mattey (1999) use unit prices computed from the same data to study patterns of price dispersion across several industries. The former paper focuses on issues regarding the persistence of prices over time and their correlation with producer sizes, while the latter explores the links between industrylevel inflation and price dispersion.

${ }^{9}$ Prices are deflated to 1987 dollars using the ready-mixed concrete industry's output deflator from the NBER Productivity Database.

${ }^{10}$ Most ready-mixed concrete plants in the U.S. during my sample period were single-unit firms (though this fraction has been falling over time). For example, 3749 firms controlled the 5319 ready-mixed plants operating in 1987. For simplicity, I assume each plant prices independently. Thus I abstract from multiproduct pricing considerations that might arise if the same firm has two plants close to each other. This assumption should be limited in impact due to the prominent role of single-unit establishments. Furthermore, I include in a robustness check below a control for the market's fraction of plants in multi-unit firms and find that this does not affect the results in any noticeable way.
} 
output and employment shares within the industry are much smaller than one-third) exempted from most CM reporting requirements. As such, these plants are not useful for my sample.

Some further data cleaning is necessary. Plant-level data contains occasional reporting and recording errors. I remove the small number of gross outliers having prices greater than five times or less than one-fifth the median in a given year. I further limit the sample to those plants with ready-mixed sales accounting for over one-half of yearly revenues. Producers who do not specialize in concrete may be operating under different conditions than specialist producers in the same market, and as such may price differently due to product bundling considerations or simply because setting optimal prices is costly and the losses from small deviations from their profit-maximizing prices are smaller for these producers. This sample criterion is not very restrictive in practice; most ready-mixed producers are specialists. Indeed there is only one seven-digit product classified within the industry, and the average fraction of plant revenues from ready-mixed concrete sales is over 90 percent in the sample. ${ }^{11}$

The final group of excluded establishments are those non-AR producers who happen to have (mostly because of incomplete reporting) physical quantities imputed by the Census Bureau. Unfortunately, these imputes are not flagged. To distinguish and remove imputed product-level data from my sample, I use the techniques described in detail in Supina (1994), Roberts and Supina (1996), and Foster, Haltiwanger, and Syverson (2003). ${ }^{12}$

After removing gross outliers, unspecialized producers, and those with imputed output quantities, my final core sample includes 12,376 plant-year price observations.

In some specifications below, I also use plant-level information on three factor prices computed using CM data. One of these, a plant's average salary (the producer's total yearly wage bill, including supplements such as Social Security payments, divided by the number of employees) is available for almost every producer in the sample. The other two are computed

\footnotetext{
${ }^{11}$ Other products produced (usually in small amounts) by ready-mixed plants typically include pre-formed concrete products such as blocks and pipe.

${ }^{12}$ Complicating the detection of imputes is the fact that different imputation methods were used by the Census Bureau. One imputation method involves calculating the average industry unit price (from establishments reporting both quantity and value data) and dividing the establishment's reported value of production by this price. These imputes can be eliminated by simply removing plant-year observations that are at the modal price for the year. The second imputation algorithm is the "hot-deck" method. This uses ratios of both plants' total value of shipments and intermediate materials expenditures to payroll in order to assign imputed quantities to similar plants. I identify hotdeck imputes by finding plants with modal values of these two ratios and remove from the sample. One should remain mindful, however, that these methods are imperfect for identifying imputed data given the absence of explicit identifiers.
} 
from the CM materials supplement, which provides input price information for a subset of plants (3,452 plant-year observations, or 28 percent of the sample). The materials supplement, like the CM product files, collects detailed product-level data by plant, except it covers intermediate material inputs rather than outputs. Total annual purchases by material input as well as their physical quantities (when feasible) are collected. For ready-mixed concrete plants, unit prices can be computed for two material inputs: cement and sand and gravel (sand and gravel are treated as a composite good by the Census Bureau). ${ }^{13}$ Despite the sparser coverage, this data allows me to isolate - at least in part — productivity selection's effect on prices by controlling for across-market factor price differences.

\section{B. Local Markets and Demand Density in the Ready-Mixed Concrete Industry}

The empirical work uses variations in demand density across geographic markets to identify the effect of spatial competition on the equilibrium price distribution. This of course raises the issue of how to suitably define markets within the industry. I use the Bureau of Economic Analysis's Component Economic Area (CEA). CEAs are collections of counties usually_but not always - centered on Metropolitan Statistical Areas (MSAs). Counties are selected for inclusion in a given CEA based upon their MSA status, worker commuting patterns, and newspaper circulation patterns, subject to the condition that CEAs must contain only contiguous counties. The selection criteria ensure that counties in a given CEA are economically intertwined. This classification process groups the roughly 3200 U.S. counties into 348 markets that are mutually exclusive and exhaustive of the land mass of the United States. ${ }^{14}$

The CEA-based market is a compromise between conflicting requirements. Markets definitions should minimize interactions between producers in different markets. While there are bound to be some cross-CEA concrete sales in reality, the high transport costs of the industry make this unlikely. Detailed industry-level shipments data from the 1977 Commodity

\footnotetext{
${ }^{13}$ These two intermediate materials account for approximately 30 percent (cement) and 15 percent (sand and gravel) of total reported industry materials costs. (Though this likely understates their cost shares. The plant data attributes a substantial portion of materials costs as "not specified by kind," which almost surely includes cement and aggregate purchases for some plants that are unable or unwilling to break down reported purchases by specific type.) Total intermediate materials costs average about 60 percent of industry revenue. The wage bill accounts for another 20 percent or so. Thus with these three inputs I am able to control for prices of inputs whose costs comprise about half of the industry's total revenue. Note that while often interchanged colloquially, cement is not synonymous with concrete. Instead, cement is a single albeit important input into concrete production.

${ }^{14}$ See Johnson (1995) for more detailed information about CEA creation.
} 
Transportation Survey support this. Ready-mixed plants shipped 94.4 percent (by weight) of their total output less than 100 miles. Discussions with industry managers also offer anecdotal evidence along these lines; stated maximum ideal delivery distances were between 30- and 45minute drives from the plant. (An additional factor minimizing cross-market shipments is that most CEA boundaries are in outlying parts of urban areas and are thus less likely to be near areas heavily populated with concrete plants.) CEAs are also not required to adhere to state boundaries, which would sometimes place unwarranted market boundaries in economically interconnected areas. Of course, markets should not be so large that the plants they contain do not respond to the same market forces, either external or caused by the actions of industry competitors. CEAs are a suitable compromise to resolve the tension between isolating markets yet ensuring the producers within them are interconnected.

The key exogenous variable in the model is demand density. To measure this empirically, I use the log of the number of construction-sector workers per square mile in the CEA-year market. Construction sector employment is obtained from County Business Patterns data aggregated at the CEA level. ${ }^{15}$ Land areas are from the City and County Data Book. As discussed above, construction sector employment density is arguably an exogenous demanddensity shifter because, while the sector buys most of the ready-mixed concrete industry's output, concrete's cost share in total construction costs is quite small.

\section{Empirical Specification}

The theory implies higher demand density should decrease the maximum, central tendency, and (given some regularity conditions on the distribution) dispersion of prices in the local market. This suggests a simple empirical model:

$$
y_{i t}=\beta_{0}+\beta_{d} \text { dens }_{i t}+X_{c, i t} B_{c}+\varepsilon_{i t}
$$

\footnotetext{
${ }^{15}$ County Business Patterns data occasionally have missing observations due to data disclosure regulations. This is a small matter in the case of the construction sector (SICs 15-17), however. The sector's ubiquity and abundance of small firms allows full disclosure of total employment in nearly all counties (employment data is withheld in roughly 1.5 percent of the county-year observations in my sample). I impute employment when missing by multiplying the number of establishments in each of nine employment ranges (which are always reported) by the midpoint of their respective employment ranges, and summing the result. The impact of using imputes is likely to be even less than their proportion indicates, as the typically small nondisclosure counties are less likely to contain non-AR ready-mixed plants.
} 
where $y_{i t}$ is a moment of the price distribution for market $i$ in year $t$, dens $s_{i t}$ is the corresponding value of demand density, $X_{c, i t}$ is a vector of (possibly time-varying) local market conditions that might also influence price moments, and $\varepsilon_{i t}$ a disturbance term. The coefficient on demand density, $\beta_{d}$, is the estimate of interest.

I use six empirical moments of local price distributions as dependent variables, two each to measure the upper bound, central tendency, and dispersion of the distribution. The upperbound price measures offer the most direct test of the hypothesized cost-selection truncation and shaping of the price distribution. The maximum price is the most obvious measure to use, but it is also the moment most vulnerable to outliers. Therefore I also run specifications using the $90^{\text {th }}$ percentile price. This equals the maximum price in markets with fewer than 10 observable prices, but it does remove the influence of outliers in large markets. The two central tendency moments are the median and the physical-output-weighted average prices. The former is used for its robustness to outliers and the latter to better capture the average transaction price in the market by giving more weight to producers who sell more output. The dispersion measures are the interquartile and 90-10 percentile ranges.

The local demand controls in $X_{c, i t}$ include an assortment of variables that plausibly shift the demand structure of the local ready-mixed concrete market through channels other than the spatial substitutability influence of demand density. ${ }^{16}$ These include demographics of the CEA: the percentage of the population that is nonwhite, the fraction over 25 years old, the proportion with at least a bachelor's degree, and the number of marriages per 1000 population. Each of these variables is aggregated from values in the 1988 City and County Data Book. The race and the marriage variables constructed from 1984 data, while the others are from the 1980 population census. I also include variables conceivably correlated with concrete demand specifically: the fraction of households owning at least two automobiles, the fraction of housing units that are owner-occupied, the median value of owner-occupied housing, and median personal income (also from 1980 and 1984). The output-weighted average specialization ratio (that is, the fraction of plant revenue from ready-mixed) in the market is included to control for any

\footnotetext{
${ }^{16}$ Of course, these other influences will not necessary bias the demand density results in the simpler specifications if they are orthogonal to my measure of demand density. It seems possible, however, that some of these control variables independently influence both local ready-mixed market structure and the overall level of construction activity (which is a key element of the demand density measure). Due to data limitations, some of these measures are CEA-specific but not CEA-year-specific. In these cases, I have attempted to use values gathered as close to the middle of the sample period as possible.
} 
systematic differences in specialization across markets. Finally, I also add the growth rate of local construction employment over the previous five years to control for short-term effects (e.g., a transient construction boom that allows relatively high-priced producers to temporarily operate). Because demand growth is included in the control vector, specifications where controls are included use only market-level price moments from 1982, 1987, and 1992.

\section{Empirical Results—Price Distributions}

\section{A. Benchmark}

Table 1 contains summary statistics for the key variables in my regressions. The price moments reported in the table are calculated at the CEA-year market level. The main sample uses only those markets in which I observe at least five producers' prices, though I show below that the basic results are robust to changes in this cutoff. As can be seen in the table, prices vary both within and across markets in the industry. The average within-market interquartile range is roughly 10 percent, and the variation across markets in this within-market dispersion measure is 8 percent. The 90-10 percentile range indicates that price variations on the order of 25 percent are not unusual within markets. The central tendency moments indicate the average median concrete price in a market is $\$ 45.56$ per cubic yard (in 1987 dollars), and the output-weighted average is roughly the same. These also vary across markets, with standard deviations of roughly seven and ten percent for the median and output-weighted mean, respectively. The measures of the upper-bound prices are mover volatile still, with the maximum price (whose average is $\$ 54.71$ ) having a standard deviation of around 20 percent. $^{17}$

Table 2 presents the benchmark estimates. The table shows the local demand density coefficient obtained when each of the six local price distribution moments are regressed on density and, if applicable, the other covariates. (I report only the demand density coefficients here for the sake of brevity, though I report the qualitative nature of the covariate estimates below.) Price moments are listed by rows, and columns denote different sets of regressors in $X_{c, i t}$.

Consider first the results from column 1, which come from specifications that regress the price moments on demand density and a set of year dummies. The correlations between demand

\footnotetext{
${ }^{17}$ Pooling all price observations together into a single distribution yields a (geometric) mean price level of $\$ 45.20$ with a standard deviation of about 15 percent. Thus, not surprisingly, prices are more variable across producers than are the central tendencies of price distributions across markets.
} 
density and price moments are in directions consistent with the theoretical framework. Increases in demand density are associated with declines in each price moment. This negative effect is significant in four of the six cases.

When the demand controls are added in column 2, the implied negative connection between demand density and the price moments becomes even stronger. All six coefficients rise in magnitude, particularly demand density's downward influence on the maximum price in the market, which is now significant. (The impact on the interquartile range remains insignificant despite the larger coefficient.) The size of the effects implied by these coefficients seems, at least for the upper bound and central tendency results, economically relevant. For example, a one standard deviation increase in density (a change equivalent to an increase from 1.6 construction workers per square mile - the geometric mean density across markets in the sample - to 6.7 workers per square mile) corresponds roughly to a 6 percent drop in the maximum market price. This is one-third of its across-market standard deviation and implies a drop in the maximum price of $\$ 3.15$ when evaluated from its mean. The same density shift implies a similarly sized 7 percent fall in the $90^{\text {th }}$ percentile price. The median (output-weighted average) price would expectedly drop 1.6 percent (3.2 percent), or about one-fourth (one-third) of a standard deviation, in response to this density increase. In levels this means the $75^{\text {th }}$ percentile density market should have a median (output-weighted average) price $\$ 0.63 / \mathrm{yd}^{3}$ $\left(\$ 1.69 / \mathrm{yd}^{3}\right)$ lower than the $25^{\text {th }}$ percentile market (this assumes median and weighted average prices are distributed symmetrically across markets, as seems reasonable given the skewness values reported in Table 1). The implied effects on within-market price dispersion are weaker, with a one standard deviation density increase implying decreases in the interquartile and 90-10 percentile ranges of 0.7 and 1.3 percent, respectively, or about one-twelfth of their standard deviations.

Panel B of Table 2 reports the qualitative features of the demand covariates estimates from the full-model specifications in column 2. While the effects of many of the controls change across price moments, perhaps the most consistent result is the positive correlation between price levels and the median household income in the market (its coefficient is positive and significant for all the upper bound and central tendency moments). This is not altogether surprising; many goods are more expensive in higher-income areas, and building materials are unlikely to be an exception to this. Prices seem to be lower in markets with high rates of owner-occupied housing. 
Price dispersion is lower in 1992 than other years, and in markets with more specialized producers. Demand growth is only significant for two of the price moments; it seems that shortrun effects of changing market sizes do not have great impacts on the shapes of equilibrium price distributions.

The results from the benchmark specification are largely consistent with theory. Upperbound prices are lower in denser markets. This truncation suggests that cost-based selection in the presence of heterogeneous producers plays an important role in determining equilibrium prices. Selections' impact also appears to carry over into average prices in the market, which are lower in high-density markets. There is some support for the implication that prices are less disperse in denser markets as well, although this appears to be concentrated in the tails of the distribution and the quantitative impact in economic terms is small. Note that even in the specifications that include demand covariates, most of the across-market variation in price moments remains unexplained. Hence cost-based selection, while having non-negligible effects, is hardly the complete story on price variation within an industry.

\section{B. Robustness - Independence of Density and Size}

The discussion above states implies that in markets where spatial competition is important, it is density specifically, rather than just market size, that drives cost-based selection and the resulting price distribution effects. I can test whether the size-density distinction holds empirically with a specification that includes both demand density and demand size (logged construction employment in the local market). The results are shown in column 2 of Table 3, which corresponds to the benchmark specifications (with all demand controls included) in Table 2 but with the additional market size control added.

The demand density coefficients retain their negative signs in all cases as well as the benchmark results' patterns of significance. Their magnitudes, with the exception of the coefficient in the maximum price regression, do decline slightly. The coefficients on market size (not shown) are somewhat erratic, while negative in four cases - the $90^{\text {th }}$ percentile price, median price, and the two dispersion moments - they are significant only in the former two cases. Moreover, they are significant and positive in the maximum and output-weighted average price regressions. While one must be mindful that these coefficients reflect only the effect of size variation that is orthogonal to density variation, it is unusual that size would have an oppositely 
signed (and significant) impact on two moments meant to measure the same shape attributes of the price distribution.

The results of this exercise indicate that despite the obvious link between market density and size, much of density's impact is independent of size effects. Thus spatial substitutability specifically, and not just overall size, shapes the cost and price distributions of market establishments.

\section{Robustness-Nonlinear Density Effects}

To see if demand density's impact on the price distribution is nonlinear, I estimate a specification that includes the square of demand density as a covariate. The results are in column 3 of Table 3 . There is very little difference between these results and those from the benchmark estimation. Three of the coefficients do not change at all to at least three decimal places, and the remaining rise insignificantly. The unreported quadratic density coefficients are positive for every price moment, though only significant in the case of the $90^{\text {th }}$ percentile price level and the two central tendency moments. So while the impact of demand density may fade somewhat at higher density levels, this effect is quantitatively weak.

\section{Robustness-Sample Market Selection Criteria}

For inclusion in my benchmark sample, I require that a market has at least five readymixed producers with non-imputed price data. Here I check to see if changing this exclusion criterion affects the results. Columns 4 and 5 of Table 3 show the demand density coefficients obtained when the cutoff levels for the minimum number of plants are instead (respectively) two and ten. Of course, the sample size is larger in the former case (927 markets meet the looser requirement) and smaller in the latter (318 markets).

Under either alternative exclusion condition, the results largely coincide with the benchmark results. Demand density's estimated negative impacts on the median price and interquartile price range rise in magnitude somewhat in the two-plant-minimum sample, but little else changes substantially. This characterization also holds for the ten-plant-minimum sample, except there is no corresponding increase in the size of the density coefficient; indeed, it falls slightly. This rise in the small-market sample and fall in the larger-market sample may be a manifestation of the weak nonlinearity in density's influence discussed above. 


\section{E. Robustness-Multi-unit Firms}

As noted above, the theoretical framework assumes that each production unit prices independently, as if it is its own profit-maximizing unit. However, multiproduct firms when making optimal pricing decisions account for the ability of their products to cannibalize each others' market shares. In the case of ready-mixed concrete, firms that own several plants in a single market would be expectedly be taking such considerations into account when setting prices. Thus the implications for shifts in the shape of the price distribution discussed above may not necessarily obtain. ${ }^{18}$

Such concerns are tempered in this industry (at least during the sample period) because, as discussed previously, most of the establishments are the only concrete plant of their owning firm. However, those plants with price available data are more likely to be larger (and thus more likely to be a part of a multi-unit firm), so my sample contains a greater fraction of multi-unit establishments than is their overall proportion. As a straightforward check for their influence, I estimate a specification where I include in $X_{c, i t}$ the fraction of market establishments that belong to a multi-unit firm. The results are reported in column 6 of Table 3.

There is very little difference between these regressions and the benchmark findings. Any changes observed in the demand density coefficients are miniscule. Multi-unit firm pricing does not seem to have any great impact on how equilibrium price distributions change with demand density in this industry.

\section{F. Robustness-Density Measure}

The demand density measure simply divides total construction sector employment in a market by the area of the market. Both of these components are aggregated from the county level. A sensible alternative measure would aggregate the county-level densities in a market by weighting them by the counties' construction sector employment. I construct this alternative demand density measure and use it in the specification reported in column 7 of Table 3.

The qualitative patterns of the benchmark results remain, with the exception of the outcomes from the maximum price regression, where the density coefficient is positive and

\footnotetext{
${ }^{18}$ It is not clear which direction multi-unit firm pricing decisions will alter the observed patterns from those implied by the theory. Presumably, a market dominated by a multi-unit producers would exhibit less price variation. The impact on the upper-bound and average prices vis-à-vis the single-unit scenario is not obvious.
} 
insignificant. Since both density measures have roughly equal standard deviations, the smaller coefficients in this specification indicate that the implied impact of the alternative demand density measure is smaller than that of the benchmark.

\section{G. Robustness-Input Price Effects}

One possible concern regarding the above results is that they reflect patterns in input price variations, rather than differences in true technical efficiency levels. While selection among heterogeneous producers in fact depends on cost differences regardless of whether they are sourced from input prices or efficiency, most models abstract from such distinctions. Thus it is possible that the patterns observed above, particularly those regarding the demand density's effect on the upper bounds and central tendencies of local price distributions, obtain because simply because input prices are lower in dense markets rather than selection being more stringent. However, I observe three plant-specific input prices for a subset of my data: (the composite) sand and gravel, cement, and labor (using the average salary). I use these to separate the influence of productivity selection from factor price differences.

The broad patterns seen in these input prices yield mixed implications about their possible influence on the results above. Table 4 contains a host of descriptive statistics obtained using the subsample of establishments for which I observe these input prices. Panel B contains the correlations among plant-level prices. Not surprisingly, producers that pay more for their intermediate inputs charge higher prices; higher sand/gravel and cement prices are positively correlated with output price. However, average salary is negatively correlated with the readymixed price of the producer. ${ }^{19}$ None of these correlations say anything about the relationship between demand density in a market and the relationship between input and output prices, however.

\footnotetext{
${ }^{19}$ Some further discussion of these input prices is appropriate. Some ready-mixed concrete producers mine sand and gravel on the factory site. Producers who obtain all of such inputs on site will not be included in the input-price subsample, since plants report only materials purchases from other establishments (though these other plants could be owned by the same firm, in which case they are still to report the "full economic value" of the materials purchases as with purchases from arms-length suppliers). While I do not directly observe if producers have on-site mining operations, the vast majority of industry plants have materials' revenue shares that are narrowly distributed around the industry average share. Given that gravel and stone are major intermediate inputs, materials costs at these levels suggest on-site mining is the exception rather than the rule. As for the average salary measure, I am of course abstracting from the possibility that wage variation reflects differences in the quality of labor inputs. It is possible, for example, that higher-wage workers work at more productive establishments who are still able to pass along the resulting cost advantage to their customers in lower prices.
} 
To see this relationship more directly, consider the correlation coefficients reported in Panel $\mathrm{C}$ of Table 4 . The panel show the covariance patterns between a market's demand density and the median of observed input and output prices in the market. The plant-level comovement between output and input prices seen above is reflected in the patterns of market medians. However, consider the correlations between these prices and demand density. While as with ready-mixed, cement tends to be less expensive in denser markets, sand and gravel prices as well as average salaries are higher. Therefore at first glance it seems unlikely that the lower readymixed prices observed in denser markets arise simply as the result of lower input costs.

To more rigorously test for this invariance of the key results to input price variation, I rerun the benchmark models, now including the input price moments corresponding to the readymixed price moment used as the dependent variable. That is, the interquartile ranges of cement, sand and gravel, and average salary are included in the interquartile price dispersion regressions, the median input prices in the median regressions, and so on. The results are presented in Table $5 .^{20}$

Column 1 presents the results from the specification that excludes all demand controls but year dummies, while column 2 contains the full-covariate model results. Notice first the correspondence between input and output price moments. The results observed in the median correlations above remain prevalent in this specification. In every case, a higher input price moment in a market corresponds to an increase in the same moment of ready-mixed prices, and this effect is statistically significant in virtually every instance as well. Even average salaries, despite having raw correlations that suggest a negative comovement with ready-mixed price levels, have a positive impact once I control for demand density and the other input price moments. It appears that these input price controls do absorb ready-mixed price variation arising from input cost differences.

The demand density coefficients now capture the density effects on the equilibrium price distribution that are independent of major input price differences. The results in Table 5 indicate that the relationships seen in the benchmark results remain. The demand density coefficients are

\footnotetext{
${ }^{20}$ The results in this table and in the reported market-level correlations in Table 4 are obtained from a sample comprised of the 575 market-year observations for which I observe at least two plants with both output and input price data. I use this smaller minimum-producer cutoff here because of the sparser coverage of the input price data. Results using the five-producer cutoff of the benchmark specification (which cuts the sample down to just over 200 market-year observations rather than the 575 here) were roughly equivalent in magnitude to those reported below, but not surprisingly less precisely estimated and as such were less likely to be statistically distinguishable from zero.
} 
negative in all regressions but one. They are significant for the upper bound and central tendency moments, while insignificant for the dispersion moments. Considerably larger impacts are implied for median and output-weighted average prices here. This likely results because the input price moments control for the unconditional positive correlations between demand density, average salary, and sand and gravel prices, that would otherwise tend to bias downward the estimated impact of demand density on average ready-mixed prices.

Therefore it appears that demand density's shaping of the equilibrium price distribution arises from selection on more efficient producers, as theorized, and not merely through coincidental relationships between density and input prices. Indeed, its impact on the central tendency of the price distribution is larger once the influence of input prices is accounted for.

\section{Discussion and Conclusion}

This paper has explored how differences in the intensity of spatial competition across markets are manifested in equilibrium prices. Standard models predict that, ceteris paribus, price should fall as producer density (the number of producers per unit area), since this raises substitution possibilities for consumers and lowers optimal markups. I find empirical support for this in a case study of the ready-mixed concrete industry: average prices are lower in denser markets.

However, I also find that there are considerable within-market price differences, and that this dispersion as well as upper bound prices also fall with density. These observations cannot be explained by homogeneous-producer models of competition that are commonly appealed to (even if noisy price measurement is present). On the other hand, heterogenous-producer models where production costs differ are able to account for the empirical patterns. These models imply a competition-driven selection effect on equilibrium prices that is absent from homogeneousproducer frameworks. As more intense competition drives out high-cost producers, upper-bound prices, average prices, and price dispersion all decline, as seen in the data.

An advantage of testing for these effect in the ready-mixed concrete industry is that the measured price differences are in response to changes in concrete demand density, which is an arguably exogenous shifter of the intensity of competition across local concrete markets. Thus the price effects of competition seen here can be reasonably seen to be causal. The responses are economically nontrivial and robust to several alternative empirical modeling assumptions. 
Furthermore they do not simply result from across-market differences in input price distributions, suggesting that selection on actual efficiency differences drives the connection between the equilibrium cost and price distributions.

While these empirical results were derived using data from a single industry, they seem likely to apply more generally. The spatial nature of competition that dominates the ready-mixed concrete industry is also important in many other industries. Indeed, spatial competition is probably weaker in manufacturing industries than in the service, retail, or wholesale trades, where the mechanisms explored here could are likely to play an even larger role. Furthermore, the body of evidence showing producer cost heterogeneity exists and is important to describing plant and firm survival continues to grow. The presence of cost-based selection means the link between competition and market prices that has been the focus of a large literature is likely to go beyond average price effects alone.

Still, much is left to be learned about the connection between the intensity of competition and the shape of the equilibrium price distribution. The empirical models here leave a large amount of the across-market variation in price moments unexplained. Surely some of this is due to the coarse nature of the spatial measures - average market density measures rather than detailed, location-specific interactions - and could be reconciled with more detailed data. There are also likely other ways (often not measurable) that product differentiation arises, such as variation in the services that come bundled with manufactured outputs, that may explain some of remaining variation. These areas seem ripe for future research. 


\section{References}

Asplund, Marcus and Volker Nocke, "Firm Turnover in Imperfectly Competitive Markets," Penn Institute for Economic Research Working Paper 03-010, 2003.

Baily, Martin Neil, Charles Hulten, and David Campbell. "Productivity Dynamics in Manufacturing Plants.” Brookings Papers on Economic Activity. Microeconomics, 1992, 187-249.

Beaulieu, Joe and Mattey, Joe. "The Effects of General Inflation and Idiosyncratic Cost Shocks on Within-Commodity Price Dispersion: Evidence from Microdata." Review of Economics and Statistics, 81(2), 1999, pp. 205-16.

Bils, Mark, Peter J. Klenow, and Oleksiy Kryvtsov. "Sticky Prices and Monetary Policy Shocks." Federal Reserve Bank of Minneapolis Quarterly Review, 27(1), 2003, 1-9.

Bresnahan, Timothy F. and Peter C. Reiss. "Entry and Competition in Concentrated Markets." Journal of Political Economy, 99(5), 1991, 977-1009.

Brown, Jeffery R. and Austan Goolsbee. "Does the Internet Make Markets More Competitive? Evidence from the Life Insurance Industry." Journal of Political Economy, 110(3), 2002, 481-507.

Chevalier, Judith and Austan Goolsbee. "Price Competition Online: Amazon Versus Barnes and Noble." Quantitative Marketing and Economics, 1(2), 2003, 203-222.

Dunne, Timothy, Mark J. Roberts, and Larry Samuelson. "The Growth and Failure of U.S. Manufacturing Plants.” Quarterly Journal of Economics, 104(4), 1989, 671-698.

Foster, Lucia, John Haltiwanger, and C. J. Krizan. "The Link Between Aggregate and Micro Productivity Growth: Evidence from Retail Trade.” NBER Working Paper 9120, 2002.

Foster, Lucia, John Haltiwanger, and Chad Syverson. "Reallocation, Firm Turnover, and Efficiency: Selection on Productivity or Profitability?.” Working Paper, 2003.

Hopenhayn, Hugo A., "Entry, Exit, and Firm Dynamics in Long Run Equilibrium," Econometrica, 60(5), 1992, 1127-1150.

Johnson, Kenneth P. "Redefinition of the BEA Economic Areas." Survey of Current Business, 75(2), 1995, 75-81.

Kashyap, Anil K. "Sticky Prices: New Evidence from Retail Catalogs." The Quarterly Journal of Economics, 110(1), 1995, 245-274.

Lach, Saul. "Existence and Persistence of Price Dispersion: An Empirical Analysis." Review of Economics and Statistics, 84(3), 2002, 433-444. 
Melitz, Marc J., "The Impact of Trade on Intra-Industry Reallocations and Aggregate Industry Productivity," Econometrica, 71(6), 2003, 1695-1725.

Ohta, H. "The Price Effects of Spatial Competition.” Review of Economic Studies, 48(2), 1981, 317-325.

Olley, Steven G. and Pakes, Ariel. "The Dynamics of Productivity in the Telecommunications Equipment Industry.” Econometrica, 64(4), 1996, pp.1263-97.

Roberts, Mark J. and Dylan Supina. "Output Price, Markups, and Producer Size.” European Economic Review, 40(3-5), 1996, 909-921.

Salop, Steven C. "Monopolistic Competition with Outside Goods." Bell Journal of Economics, 10(1), 1979, 141-156.

Sorensen, Alan T. "Equilibrium Price Dispersion in Retail Markets for Prescription Drugs." Journal of Political Economy, 108(4), 2000, 833-850.

Supina, Dylan. "Price and Markup Dispersion Among U.S. Manufacturing Plants." Ph.D. Dissertation, Pennsylvania State University, 1994.

Syverson, Chad. "Market Structure and Productivity: A Concrete Example." Journal of Political Economy, Forthcoming, 2004a.

Syverson, Chad. "Product Substitutability and Productivity Dispersion." Review of Economics and Statistics, 86(2), 2004b, 534-550.

U.S. Bureau of Labor Statistics. Trends in Multifactor Productivity, 1948-81. Bulletin 2178, Washington, DC: Government Printing Office, 1983. 
Table 1: Descriptive Statistics

\begin{tabular}{cccccc}
\hline Variable & Mean & Std. Dev. & Skewness & IQ Range & $90-10 \%$ ile \\
\hline Maximum Price & 4.002 & 0.190 & 2.587 & 0.205 & 0.376 \\
90 ${ }^{\text {th }}$ Percentile Price & 3.942 & 0.149 & 3.378 & 0.154 & 0.299 \\
Median Price & 3.819 & 0.067 & 0.386 & 0.040 & 0.129 \\
Output-Weighted Avg. Price & 3.808 & 0.100 & -1.790 & 0.095 & 0.210 \\
Price Dispersion (IQ Range) & 0.093 & 0.081 & 1.746 & 0.098 & 0.182 \\
Price Dispersion (90-10 Range) & 0.242 & 0.185 & 2.804 & 0.172 & 0.354 \\
$\quad$ Demand Density & 0.491 & 1.413 & 0.118 & 1.704 & 3.552 \\
exp(Demand Density) & 4.728 & 11.14 & 6.083 & 3.120 & 10.13 \\
(Demand Density) & 2.235 & 3.434 & 2.682 & 2.812 & 6.331 \\
$\quad$ Demand & 9.233 & 1.041 & 0.353 & 1.563 & 2.712 \\
Alt. Demand Density Measure & 1.741 & 1.458 & 0.018 & 2.039 & 3.878 \\
Ready-Mixed Price Level & & & & & \\
(12,376 plants), \$1987 & 45.68 & 7.045 & 4.815 & 3.134 & 12.66 \\
Ready-Mixed Logged Price & 3.811 & 0.143 & -0.452 & 0.069 & 0.277 \\
(12,376 plants), \$1987 & & & & & \\
\hline
\end{tabular}

Notes: This table reports descriptive statistics for the primary variables of interest in empirical tests below. Unless otherwise noted, statistics are computed across the 795 market-year observations in the core sample. Note that price moments are computed from local logged price distributions; for example, the average (across market-years) of within-market interquartile logged price ranges is 0.093 . Demand density is measured as the log of the number of construction sector employees per square mile in a market-year (the alternative density measure is an employment-weighted average of county-level densities in the market-year). Demand is simply the logged number of construction sector employees. 
Table 2. Benchmark Results_-Local Price Distribution Moments

A. Demand Density Coefficients

\begin{tabular}{cccc}
\hline Dependent Variable & Statistic & {$[1]$} & {$[2]$} \\
\hline Maximum Price & $\mathrm{R}^{2}$ & 0.014 & 0.107 \\
& Demand Density & -0.004 & $-0.042^{*}$ \\
& & $(0.006)$ & $(0.010)$ \\
$90^{\text {th }}$ Percentile Price & $\mathrm{R}^{2}$ & 0.049 & 0.144 \\
& Demand Density & $-0.018^{*}$ & $-0.047^{*}$ \\
& & $(0.005)$ & $(0.009)$ \\
Median Price & $\mathrm{R}^{2}$ & 0.096 & 0.122 \\
& Demand Density & $-0.006^{*}$ & $-0.011^{*}$ \\
& & $(0.002)$ & $(0.003)$ \\
Output-Weighted & $\mathrm{R}^{2}$ & 0.059 & 0.089 \\
Average Price & Demand Density & $-0.009^{*}$ & $-0.022^{*}$ \\
& & $(0.003)$ & $(0.005)$ \\
Price Dispersion & $\mathrm{R}^{2}$ & 0.000 & 0.121 \\
(Interquartile Range) & Demand Density & -0.000 & -0.005 \\
& & $(0.003)$ & $(0.008)$ \\
Price Dispersion & $\mathrm{R}^{2}$ & 0.051 & 0.117 \\
(90-10 Range) & Demand Density & $-0.011^{*}$ & $-0.026^{*}$ \\
& & $(0.005)$ & $(0.010)$ \\
Year Dummies & & & \\
Demand Controls & & Yes & Yes \\
\hline
\end{tabular}

Notes: This panel shows the estimated coefficients on demand density when various moments of the local price distributions are regressed on demand density and (when applicable) a set of demand controls. Specifications are by column and dependent variables by row. The sample consists of 795 region-year observations (609 in the specification that includes demand controls - see text for details) with at least five plants for which I have non-imputed output price data. Reported standard errors are robust to heteroskedasticity, and an asterisk denotes significance at the 5 percent level. 
B. Significance of Demand Controls

\begin{tabular}{|c|c|c|}
\hline Dependent Variable & Negative and Significant & Positive and Significant \\
\hline Maximum Price & Married, Autos2 & MedIncome \\
\hline $90^{\text {th }}$ Percentile Price & Married, Occup, Autos2 & MedIncome \\
\hline Median Price & $\begin{array}{l}1992 \text { Dummy, Occup, } \\
\text { MedHouse }\end{array}$ & $\begin{array}{l}\text { Over25, MedIncome, Demand } \\
\text { Growth }\end{array}$ \\
\hline $\begin{array}{l}\text { Output-Weighted } \\
\text { Average Price }\end{array}$ & Occup & Over25, MedIncome \\
\hline $\begin{array}{c}\text { Price Dispersion } \\
\text { (Interquartile Range) }\end{array}$ & $\begin{array}{l}1992 \text { Dummy, Spec, Demand } \\
\text { Growth }\end{array}$ & 1987 Dummy \\
\hline $\begin{array}{l}\text { Price Dispersion } \\
\text { (90-10 Range) }\end{array}$ & $\begin{array}{l}1992 \text { Dummy, Nonwhite, } \\
\text { Over25, Auto2, Spec }\end{array}$ & 1987 Dummy, MedIncome \\
\hline
\end{tabular}

Notes: This panel shows, by dependent variable, the significance of the demand controls included in the specification corresponding to column 2 in panel A. All demand controls are included in each regression; those not reported were statistically insignificant.

Key to Demand Controls:

Married-Fraction of population that is married

Nonwhite-Fraction of population that is non-white

College-Fraction of population with college education

Over25-Fraction of population over 25 years old

MedIncome-Logged median household income

Auto2 - Fraction of households with at least two cars

Occupied-Fraction of owner-occupied housing units

MedHouse - Logged value of median home

Demand Growth-Demand growth over past 5 years (log change in construction sector employees)

Spec-Output-weighted average revenue share of ready-mixed concrete among concrete plants 
Table 3. Robustness Checks

\begin{tabular}{|c|c|c|c|c|c|c|c|c|}
\hline Dependent Variable & Statistic or Coefficient & {$[1]$} & {$[2]$} & {$[3]$} & [4] & {$[5]$} & {$[6]$} & [7] \\
\hline \multirow[b]{2}{*}{ Maximum Price } & $\mathrm{R}^{2}$ & 0.107 & 0.134 & 0.114 & 0.184 & 0.123 & 0.108 & 0.078 \\
\hline & Demand Density & $\begin{array}{l}-0.042 * \\
(0.010)\end{array}$ & $\begin{array}{l}-0.056^{*} \\
(0.011)\end{array}$ & $\begin{array}{l}-0.044^{*} \\
(0.010)\end{array}$ & $\begin{array}{l}-0.040 * \\
(0.007)\end{array}$ & $\begin{array}{l}-0.043^{*} \\
(0.015)\end{array}$ & $\begin{array}{l}-0.043 * \\
(0.010)\end{array}$ & $\begin{array}{c}0.004 \\
(0.008)\end{array}$ \\
\hline \multirow[b]{2}{*}{$90^{\text {th }}$ Percentile Price } & $\mathrm{R}^{2}$ & 0.144 & 0.154 & 0.162 & 0.145 & 0.247 & 0.144 & 0.106 \\
\hline & Demand Density & $\begin{array}{l}-0.047^{*} \\
(0.009)\end{array}$ & $\begin{array}{l}-0.041^{*} \\
(0.010)\end{array}$ & $\begin{array}{l}-0.050 * \\
(0.009)\end{array}$ & $\begin{array}{l}-0.046^{*} \\
(0.007)\end{array}$ & $\begin{array}{l}-0.041 * \\
(0.010)\end{array}$ & $\begin{array}{l}-0.047 * \\
(0.009)\end{array}$ & $\begin{array}{c}-0.029 * \\
0.007)\end{array}$ \\
\hline \multirow[b]{2}{*}{ Median Price } & $\mathrm{R}^{2}$ & 0.122 & 0.134 & 0.132 & 0.114 & 0.244 & 0.122 & 0.117 \\
\hline & Demand Density & $\begin{array}{l}-0.011 * \\
(0.003)\end{array}$ & $\begin{array}{c}-0.007 * \\
(0.003)\end{array}$ & $\begin{array}{l}-0.011 * \\
(0.004)\end{array}$ & $\begin{array}{l}-0.018 * \\
(0.004)\end{array}$ & $\begin{array}{l}-0.009 * \\
(0.004)\end{array}$ & $\begin{array}{l}-0.010 * \\
(0.003)\end{array}$ & $\begin{array}{l}-0.008 * \\
(0.003)\end{array}$ \\
\hline $\begin{array}{l}\text { Output-Weighted } \\
\text { Average Price }\end{array}$ & $\begin{array}{c}\mathrm{R}^{2} \\
\text { Demand Density }\end{array}$ & $\begin{array}{c}0.089 \\
-0.022 * \\
(0.005)\end{array}$ & $\begin{array}{c}0.108 \\
-0.016^{*} \\
(0.005)\end{array}$ & $\begin{array}{c}0.114 \\
-0.024^{*} \\
(0.005)\end{array}$ & $\begin{array}{c}0.078 \\
-0.026^{*} \\
(0.004)\end{array}$ & $\begin{array}{c}0.235 \\
-0.022 * \\
(0.007)\end{array}$ & $\begin{array}{c}0.092 \\
-0.021 * \\
(0.005)\end{array}$ & $\begin{array}{c}0.077 \\
-0.016^{*} \\
(0.004)\end{array}$ \\
\hline $\begin{array}{c}\text { Price Dispersion } \\
\text { (Interquartile Range) }\end{array}$ & $\begin{array}{c}\mathrm{R}^{2} \\
\text { Demand Density }\end{array}$ & $\begin{array}{l}0.121 \\
-0.005 \\
(0.008)\end{array}$ & $\begin{array}{c}0.121 \\
-0.004 \\
(0.008)\end{array}$ & $\begin{array}{c}0.127 \\
-0.005 \\
(0.008)\end{array}$ & $\begin{array}{c}0.094 \\
-0.014 \\
(0.008)\end{array}$ & $\begin{array}{c}0.256 \\
-0.014 \\
(0.012)\end{array}$ & $\begin{array}{c}0.126 \\
-0.006 \\
(0.008)\end{array}$ & $\begin{array}{c}0.119 \\
-0.001 \\
(0.004)\end{array}$ \\
\hline \multirow[b]{2}{*}{$\begin{array}{l}\text { Price Dispersion } \\
\text { (90-10 Range) }\end{array}$} & $\mathrm{R}^{2}$ & 0.117 & 0.117 & 0.118 & 0.085 & 0.243 & 0.117 & 0.111 \\
\hline & Demand Density & $\begin{array}{c}-0.026^{*} \\
(0.010)\end{array}$ & $\begin{array}{c}-0.025^{*} \\
(0.010)\end{array}$ & $\begin{array}{c}-0.026^{*} \\
(0.010)\end{array}$ & $\begin{array}{c}-0.024 * \\
(0.008)\end{array}$ & $\begin{array}{c}-0.019 \\
(0.010)\end{array}$ & $\begin{array}{c}-0.026^{*} \\
(0.009)\end{array}$ & $\begin{array}{c}-0.015^{*} \\
(0.007)\end{array}$ \\
\hline
\end{tabular}

Notes: This panel shows results from various robustness checks. Year and demand controls are included in all specifications. Unless otherwise noted, sample consists of 609 CEA-year observations. Reported standard errors are robust to heteroskedasticity, and an asterisk denotes significance at the 5 percent level. The key to specifications by column: [1] benchmark results (for comparison purposes); [2] including market size control; [3] including quadratic density term; [4] 2-plant minimum for market-year cells, (927 observations); [5] 10-plant minimum for market-year cells, (318 observations); [6] multi-plant firm share included; [7] CEA density is population-weighted average county density 
Table 4. Descriptive Statistics from Subsample with Available Input Prices

A. Summary Statistics for Input Price Sample

\begin{tabular}{cccccc}
\hline Price & Mean & SD & Skewness & IQ Range & $90-10 \%$ ile \\
\hline Ready-Mixed & 46.155 & 7.700 & 1.894 & 7.859 & 16.879 \\
Sand \& Gravel & 6.377 & 2.316 & 1.047 & 3.047 & 5.533 \\
Cement & 58.570 & 12.663 & 2.467 & 14.958 & 27.913 \\
Avg. Salary & 22.114 & 9.688 & 1.055 & 12.299 & 23.288
\end{tabular}

Notes: This panel shows descriptive statistics for the 3452 plant-year observations for which I observe all three input prices (sand/gravel, cement, and average salary).

B. Plant-Level Prices, Correlation Coefficients

\begin{tabular}{c|cccc} 
& Ready-Mixed & Sand \& Gravel & Cement & Avg. Salary \\
\hline Ready-Mixed & 1 & & & \\
Sand \& Gravel & 0.120 & 1 & 1 & \\
Cement & 0.220 & 0.011 & -0.102 & 1 \\
Avg. Salary & -0.067 & -0.106 &
\end{tabular}

Notes: This panel shows simple correlations between output and input prices across 3452 plantyear observations. All prices are in logarithms of 1987 dollars.

C. Demand Density and Market-Level Median Prices, Correlation Coefficients

\begin{tabular}{c|ccccc} 
& Demand Dens. Ready-Mixed Sand \& Gravel & Cement & Avg. Salary \\
\hline Demand Density & 1.000 & & & & \\
Ready-Mixed & -0.143 & 1.000 & & & \\
Sand \& Gravel & 0.110 & 0.184 & 1.000 & & \\
Cement & -0.242 & 0.345 & -0.045 & 1.000 & \\
Avg. Salary & 0.326 & -0.014 & -0.136 & -0.115 & 1.000
\end{tabular}

Notes: This panel shows simple correlations between demand density and median prices (output and inputs) across the 575 market-year observations that include at least two producers with all input price data available. All prices are in logarithms of 1987 dollars. 
Table 5. Controlling for Input Price Moments

\begin{tabular}{|c|c|c|c|}
\hline Dependent Variable & Statistic or Coefficient & [1] & [2] \\
\hline \multirow{5}{*}{ Maximum Price } & $\mathrm{R}^{2}$ & 0.192 & 0.238 \\
\hline & Demand Density & $\begin{array}{l}-0.016^{*} \\
(0.005)\end{array}$ & $\begin{array}{c}-0.044 * \\
(0.009)\end{array}$ \\
\hline & Sand and Gravel & $\begin{array}{l}0.085^{*} \\
(0.020)\end{array}$ & $\begin{array}{l}0.085^{*} \\
(0.031)\end{array}$ \\
\hline & Cement & $\begin{array}{l}0.168^{*} \\
(0.044)\end{array}$ & $\begin{array}{c}0.155^{*} \\
(0.053)\end{array}$ \\
\hline & Salary & $\begin{array}{l}0.127^{*} \\
(0.021)\end{array}$ & $\begin{array}{c}0.125^{*} \\
(0.040)\end{array}$ \\
\hline \multirow{5}{*}{$90^{\text {th }}$ Percentile Price } & $\mathrm{R}^{2}$ & 0.187 & 0.236 \\
\hline & Demand Density & $\begin{array}{c}-0.017^{*} \\
(0.005)\end{array}$ & $\begin{array}{c}-0.045^{*} \\
(0.008)\end{array}$ \\
\hline & Sand and Gravel & $\begin{array}{l}0.080^{*} \\
(0.019)\end{array}$ & $\begin{array}{c}0.075^{*} \\
(0.031)\end{array}$ \\
\hline & Cement & $\begin{array}{l}0.166^{*} \\
(0.037)\end{array}$ & $\begin{array}{c}0.161^{*} \\
(0.048)\end{array}$ \\
\hline & Salary & $\begin{array}{l}0.119^{*} \\
(0.021)\end{array}$ & $\begin{array}{c}0.111^{*} \\
(0.042)\end{array}$ \\
\hline \multirow{5}{*}{ Median Price } & $\mathrm{R}^{2}$ & 0.209 & 0.262 \\
\hline & Demand Density & $\begin{array}{c}-0.017^{*} \\
(0.005)\end{array}$ & $\begin{array}{c}-0.037^{*} \\
(0.009)\end{array}$ \\
\hline & Sand and Gravel & $\begin{array}{l}0.093^{*} \\
(0.016)\end{array}$ & $\begin{array}{c}0.085^{*} \\
(0.022)\end{array}$ \\
\hline & Cement & $\begin{array}{l}0.183^{*} \\
(0.044)\end{array}$ & $\begin{array}{l}0.148^{*} \\
(0.063)\end{array}$ \\
\hline & Salary & $\begin{array}{l}0.103^{*} \\
(0.020)\end{array}$ & $\begin{array}{l}0.086^{*} \\
(0.029)\end{array}$ \\
\hline Year Dummies & & Yes & Yes \\
\hline Demand Controls & & No & Yes \\
\hline
\end{tabular}

Notes: This table shows results obtained when input-price moments are included in the outputprice-moment regressions (coefficients for covariates have been suppressed). The sample consists of 575 region-year observations (362 in the specification that includes demand controls) with at least two plants for which I have non-imputed output and input price data. Reported standard errors are robust to heteroskedasticity, and an asterisk denotes significance at the 5 percent level. 
Table 5 (continued). Controlling for Input Price Moments

\begin{tabular}{|c|c|c|c|}
\hline Dependent Variable & & [1] & [2] \\
\hline \multirow{5}{*}{$\begin{array}{l}\text { Output-Weighted } \\
\text { Average Price }\end{array}$} & $\overline{\mathrm{R}^{2}}$ & 0.131 & 0.159 \\
\hline & Demand Density & $\begin{array}{c}-0.016^{*} \\
(0.006)\end{array}$ & $\begin{array}{c}-0.040 * \\
(0.011)\end{array}$ \\
\hline & Sand and Gravel & $\begin{array}{l}0.093^{*} \\
(0.019)\end{array}$ & $\begin{array}{c}0.099^{*} \\
(0.027)\end{array}$ \\
\hline & Cement & $0.168^{*}$ & $0.144^{*}$ \\
\hline & Salary & $\begin{array}{l}0.086^{*} \\
(0.022)\end{array}$ & $\begin{array}{c}0.072 \\
(0.037)\end{array}$ \\
\hline \multirow{5}{*}{$\begin{array}{l}\text { Price Dispersion } \\
\text { (Interquartile Range) }\end{array}$} & $\mathrm{R}^{2}$ & 0.055 & 0.087 \\
\hline & Demand Density & $\begin{array}{l}-0.000 \\
(0.004)\end{array}$ & $\begin{array}{l}-0.015 \\
(0.010)\end{array}$ \\
\hline & Sand and Gravel & $\begin{array}{l}0.068^{*} \\
(0.022)\end{array}$ & $\begin{array}{l}0.067 * \\
(0.034)\end{array}$ \\
\hline & Cement & $\begin{array}{l}0.175^{*} \\
(0.067)\end{array}$ & $\begin{array}{c}0.164^{*} \\
(0.081)\end{array}$ \\
\hline & Salary & $\begin{array}{c}0.030 \\
(0.025)\end{array}$ & $\begin{array}{c}0.025 \\
(0.033)\end{array}$ \\
\hline \multirow{5}{*}{$\begin{array}{c}\text { Price Dispersion } \\
\text { (90-10 Percentile Ratio) }\end{array}$} & $\mathrm{R}^{2}$ & 0.124 & 0.128 \\
\hline & Demand Density & $\begin{array}{c}0.010 \\
(0.005)\end{array}$ & $\begin{array}{l}-0.015 \\
(0.012)\end{array}$ \\
\hline & Sand and Gravel & $\begin{array}{l}0.098^{*} \\
(0.023)\end{array}$ & $\begin{array}{c}0.087^{*} \\
(0.040)\end{array}$ \\
\hline & Cement & $\begin{array}{l}0.145^{*} \\
(0.050)\end{array}$ & $\begin{array}{c}0.149^{*} \\
(0.063)\end{array}$ \\
\hline & Salary & $\begin{array}{l}0.054^{*} \\
(0.022)\end{array}$ & $\begin{array}{c}0.054 \\
(0.030)\end{array}$ \\
\hline Year Dummies? & & Yes & Yes \\
\hline Demand Controls? & & No & Yes \\
\hline
\end{tabular}

Notes: This table shows results obtained when input-price moments are included in the outputprice-moment regressions (coefficients for covariates have been suppressed). The sample consists of 575 region-year observations (362 in the specification that includes demand controls) with at least two plants for which I have non-imputed output and input price data. Reported standard errors are robust to heteroskedasticity, and an asterisk denotes significance at the 5 percent level. 